\title{
A Fractal Model for the Maximum Droplet Diameter in Gas-Liquid Mist Flow
}

\author{
Xiao-Hua Tan, Jian-Yi Liu, Xiao-Ping Li, Guang-Dong Zhang, and Chuan Tang \\ State Key Laboratory of Oil and Gas Reservoir Geology and Exploitation, Southwest Petroleum University, Chengdu 610500, China \\ Correspondence should be addressed to Xiao-Hua Tan; xiaohua-tan@163.com
}

Received 17 June 2013; Revised 18 September 2013; Accepted 22 September 2013

Academic Editor: Tirivanhu Chinyoka

Copyright (C) 2013 Xiao-Hua Tan et al. This is an open access article distributed under the Creative Commons Attribution License, which permits unrestricted use, distribution, and reproduction in any medium, provided the original work is properly cited.

\begin{abstract}
Distribution characteristics of liquid droplet size are described using the fractal theory for liquid droplet size distribution in gasliquid mist flow. Thereby, the fractal expression of the maximum droplet diameter is derived. The fractal model for maximum droplet diameter is obtained based on the internal relationship between maximum droplet diameter and the droplet fractal dimension, which is obtained by analyzing the balance between total droplet surface energy and total gas turbulent kinetic energy. Fractal model predictions of maximum droplet diameter agree with the experimental data. Maximum droplet diameter and droplet fractal dimension are both found to be related to the superficial velocity of gas and liquid. Maximum droplet diameter decreases with an increase in gas superficial velocity but increases with an increase in liquid superficial velocity. Droplet fractal dimension increases with an increase in gas superficial velocity but decreases with an increase in liquid superficial velocity. These are all consistent with the physical facts.
\end{abstract}

\section{Introduction}

Since the 1960s, coalescence and breakup phenomena of droplets in gas-liquid mist flow have obtained extensive attention in many physical and chemical process applications [1-3], such as distillation, gas absorption, and multiphase reactions. In nature, the tendency toward droplet coalescence or breakup depends on droplet size [4]. Numerous studies have shown that the main parameters influencing these phenomena are droplet size, system physical properties, and flow properties [5].

Numerous semiempirical models that predict droplet size in gas-liquid mist flow have been developed. According to Woodmansee and Hanratty [6], removal of microwaves on top of liquid film flow surges leads to atomization. Based on Woodmansee and Hanratty's [6] droplet generation assumptions, Tatterson et al. [7] derived a prediction model for droplet size. Then, an empirical binomial equation was introduced by Andreussi et al. [8] based on their own data, with the first term proportional to gas superficial velocity and the second term linked to the square root of film thickness. Ueda [9] measured size and droplet removal flow rate in upward annular gas-liquid flow. He derived the rate of droplet movement between the liquid film and the gas core by considered droplet transference rates between the gas core and the liquid film. Lastly, Ueda proposed a mean diameter model for droplets under interface tension in gas flow by assuming a gamma-like size distribution for the gas core droplets. The empirical equation contained a single term, and droplet size was proportional to the gas velocity to the power of -0.34 , which contrasted to most other equations having a power of -1.0. Sevik and Park [10] studied the assumption that the natural oscillation frequency of the liquid package is equal to the characteristic frequency of the disturbance. Under these conditions, droplets will break when resonance occurs. According to their results, Azzopardi et al. [11] derived an equation linking droplet size to the rupture of liquid packages in gas flow. Using a similar methodology, Lopes and Dukler [12] and Kocamustafaogullari et al. [13] used their own data to optimize this equation. Azzopardi et al. [14] developed a new laser optical technique to study annular flow where droplet size and axial and radial velocity are simultaneously measured and the flow conditions that droplet size distributions depend on are analyzed. Their equation, based on Tatterson et al. 
[7] and Azzopardi et al. [11], deals with the influence of coalescence by defining a mean free path between collisions. This processing method is similar to the gas kinetic theory.

Shavit and Chigier [15] were the first to observe the existence of fractal characteristics during droplet separation and jet. This observation provided the basis for using fractal theory to describe droplet size distribution. Weixing et al. [16] studied the fractal characteristics associated with the distribution of droplet sizes in the atomization process. They measured the fractal dimensions using droplet-splitting simulations. The results of this experiment led to the creation of a droplet splitting model, which uses a uniformly distributed probability function. Based on Weixing et al. [16], Zhou and $\mathrm{Yu}$ [17] measured droplet size distribution data using a dual particle dynamic analyzer and proposed a multifractal model to describe droplet dissolution characteristics. Kolmogorov described the breakup of solid particles as a discrete random process. Apte et al. [18] adopted Kolmogorov's concept and established a stochastic subgrid model for large-eddy simulation of atomizing spray. Apte et al. showed that the atomization of droplets at high relative liquid-to-gas velocity was not affected by the initial droplet size in the framework of uncorrelated breakup events. According to the description of the droplet dissolution process proposed by Kolmogorov Gorokhovski and Saveliev [19] developed a droplet distribution model in the phase space of droplet position velocity by studying the breakup of droplets at the large Weber number. This numerical method can be used to stochastically model droplet production. According to the self-similarity of droplet breakup, Liu et al. [20] introduced a finite stochastic breakup model for air-blast atomizers, which is used to simulate the process of secondary atomization. Jiang et al. [21] researched the atomization process of the coaxial air-blast atomizer on the basis of the self-similarity of droplet breakup during secondary atomization. According to the breakup time study and the motion features of droplets in gas flow, they observed the factors that affect the Sauter mean diameter (SMD), which are the liquid/gas mass flux ratio, gas jet velocity, liquid jet velocity, and liquid droplet diameter.

In this paper, the distribution characteristics of mist flow droplet size are studied using a fractal mechanism. The fractal model of maximum droplet diameter is obtained by combining the analysis of the droplets total surface energy with that of gas flow total turbulent kinetic energy balance.

\section{Model}

2.1. Distribution Characteristics of Liquid Droplet Size in GasLiquid Mist Flow. Many researchers study the distribution characteristics of liquid droplet size using statistical methods. Results show that cross-sectional distribution characteristics of liquid droplet size have fractal features [15-17]. According to fractal geometry, distribution of the fractal accumulative droplet number, $N$, and droplet diameter submit to the following scale relationship [22, 23]:

$$
N(L \geq \lambda)=\left(\frac{\lambda_{\max }}{\lambda}\right)^{D_{f}}
$$

where $\lambda_{\max }$ is the maximum droplet diameter. $D_{f}$ is the droplet fractal dimension, $0<D_{f}<2$ in two-dimensional space, and $0<D_{f}<3$ in three-dimensional space [24].

Solving the differential of (1), the liquid droplet number between $\lambda$ to $\lambda+d \lambda$ can be obtained [25]:

$$
-d N=D_{f} \lambda_{\max }^{D_{f}} \lambda^{-\left(D_{f}+1\right)} d \lambda
$$

The negative variable in (2) indicates that liquid droplet number increases along with a decrease in droplet size [26, 27] and $-d N>0$.

The cross-sectional area of gas-liquid mist flow, $A$, is expressed as

$$
A=\frac{\pi D^{2}}{4}
$$

where $D$ is the diameter of the cross-section.

In cross-section $A$, the area occupied by the droplets is

$$
A_{1}=-\int_{\lambda_{\min }}^{\lambda_{\max }} \frac{\pi \lambda^{2}}{4} d N=\frac{\pi D_{f} \lambda_{\max }^{2}}{4\left(2-D_{f}\right)}\left[1-\left(\frac{\lambda_{\min }}{\lambda_{\max }}\right)^{2-D_{f}}\right] .
$$

Generally, $0<D_{f}<2$ in two-dimensional space. In gasliquid mist flow real situation, $\lambda_{\min } / \lambda_{\max }<10^{-6}$, and $D_{f}$ is greater than 0.5 , so $\left(\lambda_{\min } / \lambda_{\max }\right)^{2-D_{f}}<10^{-3}$; (4) can be simplified as

$$
A_{1}=\frac{\pi D_{f} \lambda_{\max }^{2}}{4\left(2-D_{f}\right)}
$$

In cross-section $A$, the area occupied by gas is

$$
A_{g}=A-A_{1}=\frac{\pi D^{2}}{4}\left[1-\frac{D_{f} \lambda_{\max }^{2}}{\left(2-D_{f}\right) D^{2}}\right] \text {. }
$$

In gas-liquid mist flow, the relationship between liquid velocity, $v_{l}$, and liquid superficial velocity, $v_{\mathrm{sl}}$, is

$$
v_{\mathrm{sl}}=\frac{A_{l}}{A} v_{l} \text {. }
$$

Substituting (3) and (5) into (7), liquid superficial velocity can be expressed as

$$
v_{\mathrm{sl}}=\frac{D_{f} v_{l} \lambda_{\max }^{2}}{\left(2-D_{f}\right) D^{2}}
$$

It can be observed from (8) that $D_{f}$ is proportional to cross-sectional droplet number. An increase in $D_{f}$ indicates that the liquid carried by gas flow disperses into smaller liquid droplets (i.e., liquid coalesces into smaller liquid droplets). This conforms to the physical fact that $\lambda_{\max }$ decreases along with an increase in $D_{f}$.

Liquid droplet velocity can be synchronously measured by phase Doppler anemometry (Azzopardi and Teixeira [28]) or Ronchi grating technology (Fore and Dukler [29]). 
The results of these two methodologies are similar: when gas and liquid mix sufficiently, liquid velocity approximately equals that of gas in gas-liquid mist flow:

$$
v_{l}=v_{g} .
$$

According to the definition of velocity and superficial velocity of gas and liquid, the relationship between gas and liquid superficial velocity can be obtained from (9):

$$
v_{\mathrm{sg}}=\frac{A_{g}}{A_{l}} v_{\mathrm{sl}} .
$$

Substituting (5) and (6) into (10), the maximum droplet diameter on the basis of mist flow characteristics can be solved:

$$
\lambda_{\max }=\left[\frac{\left(2-D_{f}\right) D^{2} v_{\mathrm{sl}}}{D_{f}\left(v_{\mathrm{sg}}+v_{\mathrm{sl}}\right)}\right]^{1 / 2} .
$$

As the maximum droplet diameter, $\lambda_{\max }$, and the droplet fractal dimension, $D_{f}$, in (11) are both unknown variables, they cannot be directly solved by gas superficial velocity, $v_{\mathrm{sg}}$, and liquid superficial velocity, $v_{\mathrm{sl}}$. The internal relationship between the maximum droplet diameter, $\lambda_{\max }$, and the droplet fractal dimension, $D_{f}$, can be found by analyzing the balance relationship between the surface energy of the dispersed phase and the turbulent kinetic energy of the continuous phase. Therefore, the subsidiary condition for solving (11) is obtained.

\subsection{Droplet Total Surface Energy and Total Gas Turbulent} Kinetic Energy Balance Analysis. The droplet breakup model is applied to describe the cause of mist flow formation. According to the balance relationship between the surface energy of the dispersed phase and the turbulent kinetic energy of the continuous phase, Hinze [30] theoretically derived the maximum stability diameter of the dispersed phase in continuous fluid. Similar phenomenon also exists in gas-liquid mist flow. The maximum stability diameter of a droplet can be derived with the aid of the droplet dispersion model.

According to Adamson [31], free surface energy per unit area equals the interfacial tension per unit area in the gasliquid phase; that is,

$$
e_{S}=\sigma
$$

The total free surface energy of dispersed droplets in continuous gas flow is

$$
E_{S}=-v_{l} \sigma \int_{\lambda_{\min }}^{\lambda_{\max }} \pi \lambda d N=\frac{\pi D_{f} v_{l} \sigma \lambda_{\max }}{\left(1-D_{f}\right)} .
$$

It can be seen that the value of the droplet fractal dimension is $0<D_{f}<1$; when the total free surface energy of the dispersed droplets is greater than $0, E_{s}>$ 0 . An increase in $D_{f}$ indicates that cross-sectional droplet distribution, contact area between the gas and liquid phase, and the value of $E_{S}$ are large. In limiting cases, when $D_{f}$ equals 0 , cross-sectional droplets aggregate which leads to an extremely small contact area and $E_{S}$ tends towards 0 ; when $D_{f}$ equals 1 , tiny liquid droplets dispersed on the crosssection, $E_{S}$, tend toward infinity. An increase in the maximum droplet diameter, $\lambda_{\max }$, indicates an increase in the contact area between the gas and liquid phases. Therefore, the rule that $E_{\mathrm{S}}$ increases with an increase in $\lambda_{\max }$ and $D_{f}$ conforms to the physical definition of free surface energy.

By substituting (8) into (13), the relationship between total free surface energy of the dispersed droplets and liquid superficial velocity can be obtained:

$$
E_{S}=\frac{\pi \sigma\left(2-D_{f}\right) D^{2}}{\left(1-D_{f}\right) \lambda_{\max }} v_{\mathrm{sl}} .
$$

According to White [32] and Zhang et al. [33], gas flow's turbulent kinetic energy per unit volume can be expressed as

$$
e_{T}=\frac{3}{2} \rho_{g} \overline{v_{r}^{\prime 2}},
$$

where $\rho_{g}$ is gas density and $v_{r}^{\prime}$ is the radial velocity of gas.

Thus, the total turbulent kinetic energy of the continuous gas phase can be obtained:

$$
E_{T}=\frac{3}{2} \rho_{g} \overline{v_{r}^{\prime 2}} A v_{\mathrm{sg}} .
$$

According to Taitel et al. [34] and Chen et al. [35], gas radial velocity; approximately equals friction velocity; that is,

$$
{\overline{v_{r}^{\prime 2}}}^{1 / 2}=v_{\mathrm{sg}}\left(\frac{f_{\mathrm{sg}}}{2}\right)^{1 / 2} .
$$

The friction factor $f_{\mathrm{sg}}$ caused by gas flow is expressed as

$$
\frac{1}{\sqrt{f_{\mathrm{sg}}}}=1.14-2 \lg \left(\frac{e}{D}+\frac{21.25}{\mathrm{Re}^{0.9}}\right),
$$

where $e$ is the absolute roughness, $e=1.6 \times 10^{-6} \mathrm{~m}$. Re is the Reynolds number.

Substituting (17) into (16), the total turbulent kinetic energy of gas-liquid mist flow can be expressed as

$$
E_{T}=\frac{3}{4} f_{\mathrm{sg}} \rho_{g} A v_{\mathrm{sg}}^{3} .
$$

In high-speed gas flow, total droplet surface energy is equal to the total turbulent kinetic energy of the gas phase [36]:

$$
E_{S}=E_{T}
$$

Substituting (14) and (19) into (20), maximum droplet diameter based on the droplet dispersion model can be obtained:

$$
\lambda_{\max }=\frac{16 \sigma\left(2-D_{f}\right) v_{\mathrm{sl}}}{3 f_{\mathrm{sg}} \rho_{g}\left(1-D_{f}\right) v_{\mathrm{sg}}^{3}} .
$$

It can be seen from (21) that the maximum droplet diameter increases with a decrease in gas superficial velocity and an increase in liquid superficial velocity. This rule is consistent with physical reality. 
2.3. Fractal Model of Maximum Liquid Droplet Diameter. The droplet size distribution rule describes droplet distribution in gas-liquid mist flow. Droplet distribution is controlled by the balance relationship between total droplet surface energy and total gas turbulent kinetic energy. Therefore, the droplet fractal dimension under gas-liquid mist flow conditions can be calculated by substituting (21) into (11):

$$
A D_{f}^{2}+B D_{f}+C=0
$$

where

$$
\begin{aligned}
& A=\left(3 D f_{\mathrm{sg}} \rho_{\mathrm{g}} v_{\mathrm{sg}}^{3}\right)^{2}+256 v_{\mathrm{sg}} v_{\mathrm{sl}} \sigma^{2}+256\left(v_{\mathrm{sl}} \sigma\right)^{2}, \\
& B=-2\left[\left(3 D f_{\mathrm{sg}} \rho_{g} v_{\mathrm{sg}}^{3}\right)^{2}+256 v_{\mathrm{sg}} v_{\mathrm{sl}} \sigma^{2}+256\left(v_{\mathrm{sl}} \sigma\right)^{2}\right], \\
& C=\left(3 D f_{\mathrm{sg}} \rho_{\mathrm{g}} v_{\mathrm{sg}}^{3}\right)^{2} .
\end{aligned}
$$

Equation (22) has one solution between 0 and 1. Therefore, the liquid droplet fractal dimension in gas-liquid mist flow can be expressed as

$$
D_{f}=\frac{-B-\sqrt{B^{2}-4 A C}}{2 A} .
$$

By combining (11) with (24), the fractal expression of maximum droplet diameter under gas-liquid mist flow conditions can be obtained:

$$
\begin{aligned}
\lambda_{\max } & =\left[\frac{\left(2-D_{f}\right) D^{2} v_{\mathrm{sl}}}{D_{f}\left(v_{\mathrm{sg}}+v_{\mathrm{sl}}\right)}\right]^{1 / 2}, \\
D_{f} & =\frac{-B-\sqrt{B^{2}-4 A C}}{2 A} .
\end{aligned}
$$

Equation (25) is the analytical solution of the fractal model of maximum droplet diameter in gas-liquid mist flow. The maximum droplet diameter, $\lambda_{\max }$, and the droplet fractal dimension, $D_{f}$, can be simultaneously solved using gas superficial velocity, $v_{\mathrm{sg}}$, and liquid superficial velocity, $v_{\mathrm{sl}}$. The model proposed in this paper contains no empirical constants, and every parameter has clear physical meaning. However, other parameters are required to identify $\lambda_{\max }$ and $D_{f}$, such as the cross-sectional diameter of gas-liquid mist flow, $D$, gas density, $\rho_{g}$, and interface tension, $\sigma$.

\section{Results and Discussion}

Figure 1 shows a comparison between the proposed model's predictions and experimental results measured by Fore and Dukler [29]. Agreement between the fractal model predictions and the experimental results of Fore and Dukler in different liquid viscosity and superficial velocity conditions is obtained. Results suggest that the proposed gas-liquid mist flow maximum liquid droplet diameter model is reliable.

Figure 2 shows the relationships between maximum droplet diameter, $\lambda_{\max }$, droplet fractal dimension, $D_{f}$, and

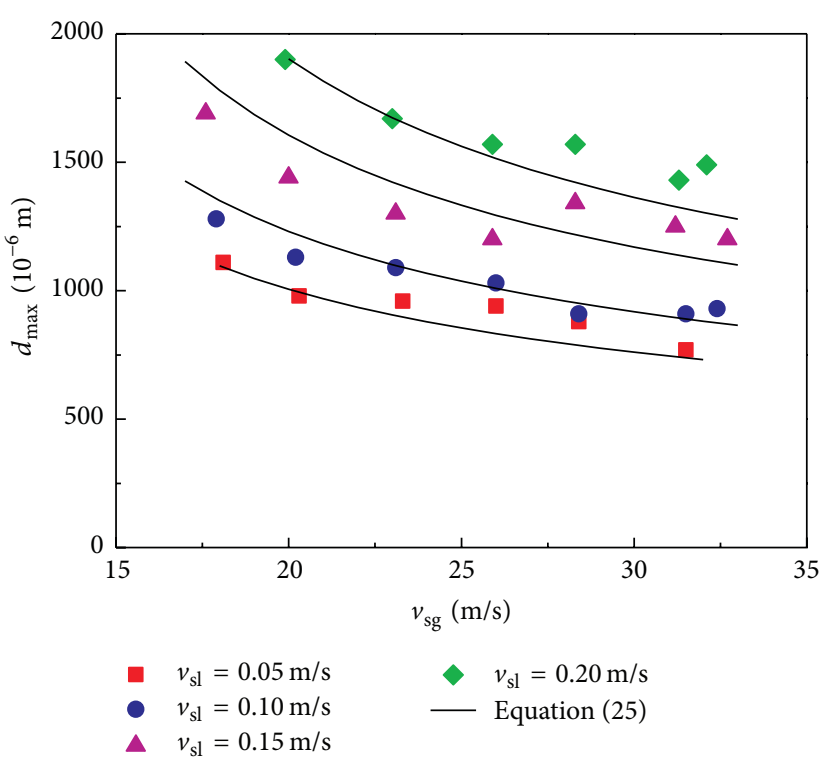

FIGURE 1: Comparison between the proposed model predictions and experimental results $\left(D=0.15 \mathrm{~m}, \sigma=0.072 \mathrm{~N} / \mathrm{m}\right.$, and $\mu_{l}=1.05 \times$ $\left.10^{-3} \mathrm{~Pa} \cdot \mathrm{s}\right)$.

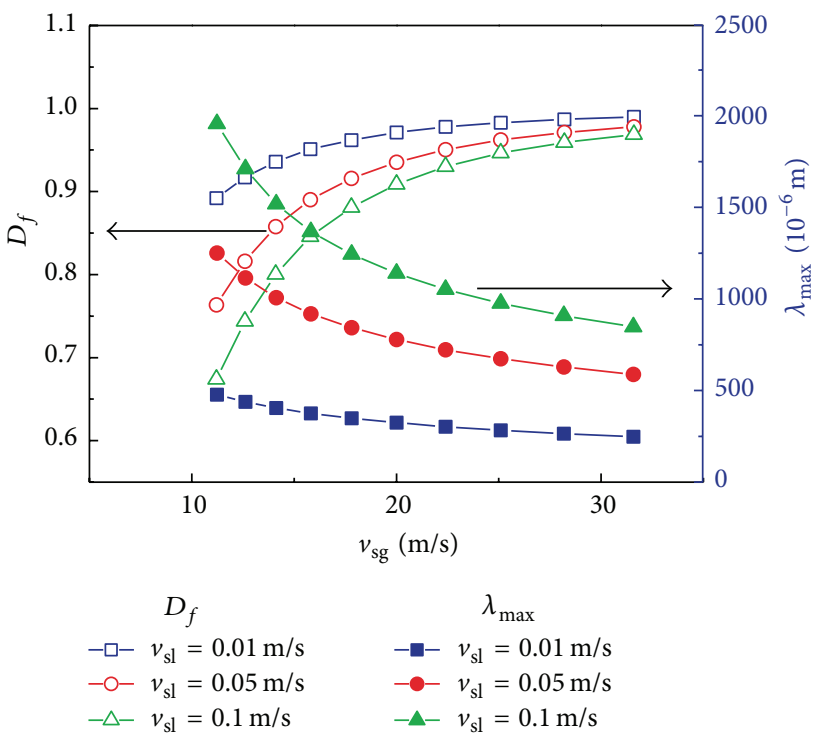

FIGURE 2: Maximum droplet diameter and droplet fractal dimension versus $v_{\text {sl }}$ at different $v_{\text {sg }}$ for gas-liquid mist flow.

gas superficial velocity, $v_{\mathrm{sg}}$, calculated by the present model. It can be seen that $\lambda_{\max }$ decreases with an increase in $v_{\mathrm{sg}}$. Inversely, $D_{f}$ increases with an increase in $v_{\mathrm{sg}}$. As $v_{\mathrm{sg}}$ increases, the turbulent kinetic energy of the gas in the gasliquid mist flow increases, which forces the original droplets to disperse into smaller droplets, making $\lambda_{\max }$ decrease and $D_{f}$ increase. These all conform to the physical facts.

Figure 3 shows the relationships between maximum droplet diameter, $\lambda_{\text {max }}$, droplet fractal dimension, $D_{f}$, and liquid superficial velocity, $v_{\mathrm{sl}}$, calculated by the present model. $\lambda_{\text {max }}$ increases with an increase in $v_{\mathrm{sl}}$. Inversely, $D_{f}$ decreases 


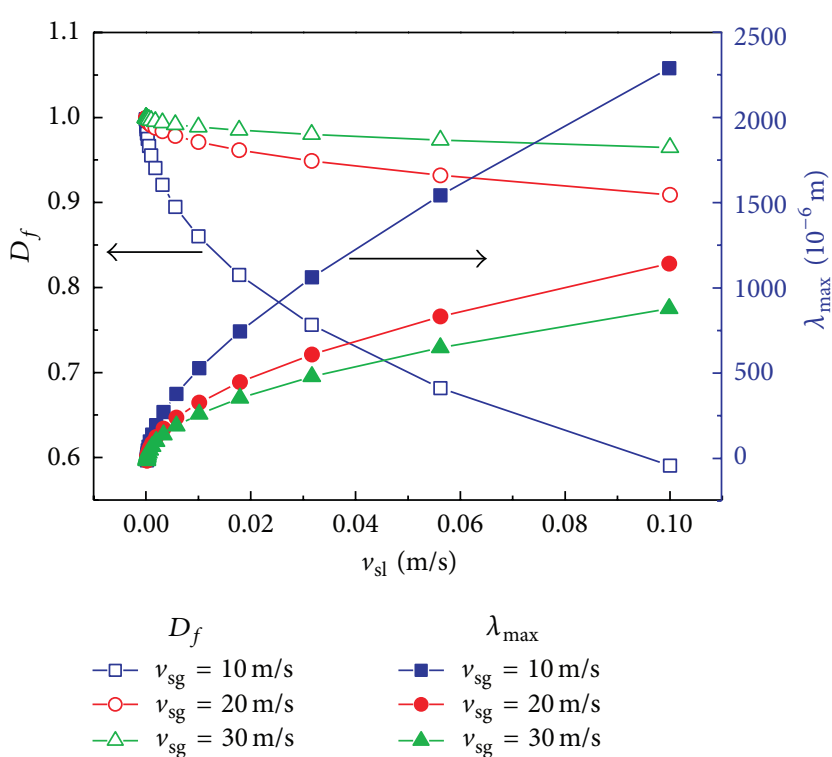

Figure 3: Maximum droplet diameter and droplet fractal dimension versus $v_{\mathrm{sg}}$ at different $v_{\mathrm{sl}}$ for gas-liquid flow.

with an increase in $v_{\mathrm{sl}}$. As $v_{\mathrm{sl}}$ increases, surface energy of the liquid in the gas-liquid mist flow increases, which forces the original droplets to coalesce into smaller droplets, making $\lambda_{\max }$ increase and $D_{f}$ decrease. These all conform to the physical facts.

\section{Conclusion}

(1) Based on liquid droplet fractal size distribution properties in gas-liquid mist flow, we describe the characteristics of droplet distribution under mist flow conditions. The fractal expression of maximum droplet diameter is derived and the internal relationship between maximum droplet diameter and droplet fractal dimension is confirmed by analyzing the balance relationship between total droplet surface energy and total gas turbulent kinetic energy. Therefore, the fractal model of the maximum droplet diameter in gas-liquid mist flow is derived. Fractal expressions of cross-sectional area occupied by gas or liquid and the superficial velocity of gas and liquid are obtained. Every parameter proposed in this paper has clear physical meaning.

(2) Agreement between predictions of the proposed fractal model and experimental measurements is obtained. Results verify the reliability of the proposed model.

(3) The influence of gas and liquid superficial velocity on maximum liquid droplet diameter, $\lambda_{\max }$, and liquid droplet fractal dimension, $D_{f}$, is analyzed. $\lambda_{\max }$ increases with a decrease in $v_{s g}$ and with an increase in $v_{\mathrm{sl}}$. $D_{f}$ increases with an increase in $v_{\mathrm{sg}}$ and with a decrease in $v_{\mathrm{sl}}$. These coincide with the physical facts.

\section{Nomenclature}

A: Cross-sectional area of a conduit, $\mathrm{m}^{2}$

$A_{\mathrm{g}}$ : Cross-sectional area occupied by gas, $\mathrm{m}^{2}$

$A_{l}$ : Cross-sectional area occupied by liquid, $\mathrm{m}^{2}$

$D$ : Conduit diameter, $\mathrm{m}$

$D_{f}$ : Droplet fractal dimensions

$E_{S}$ : Total surface free energy, $\mathrm{W}$

$E_{T}$ : Total turbulent kinetic energy, W

$e: \quad$ Absolute pipe wall roughness, $\mathrm{m}$

$e_{s}: \quad$ Surface free energy per unit volume, $\mathrm{J} / \mathrm{m}^{2}$

$e_{T}$ : Turbulent kinetic energy per unit area, $\mathrm{J} / \mathrm{m}^{3}$

$f_{\mathrm{sg}}$ : Friction factor at gas superficial velocity

$N$ : Fractal accumulative droplet number

Re: Reynolds number

$v_{g}:$ Gas velocity, $\mathrm{m} / \mathrm{s}$

$v_{l}: \quad$ Liquid velocity, $\mathrm{m} / \mathrm{s}$

$v_{\mathrm{sg}}:$ Gas superficial velocity, $\mathrm{m} / \mathrm{s}$

$v_{\mathrm{sl}}:$ Liquid superficial velocity, $\mathrm{m} / \mathrm{s}$

$v_{r}^{\prime}:$ Radial velocity, $\mathrm{m} / \mathrm{s}$

$\lambda: \quad$ Droplet diameter, $\mathrm{m}$

$\lambda_{\max }:$ Maximum droplet diameter, $\mathrm{m}$

$\lambda_{\text {min }}:$ Minimum droplet diameter, $m$

$\rho_{g}:$ Gas density, $\mathrm{kg} / \mathrm{m}^{3}$

$\rho_{l}: \quad$ Liquid density, $\mathrm{kg} / \mathrm{m}^{3}$

$\sigma:$ Interfacial tension, $\mathrm{N} / \mathrm{m}$.

\section{Subscripts}

g: Gas phase

l: Liquid phase

$s$ : Superficial

$T$ : Turbulent.

\section{Acknowledgments}

The authors are grateful for financial support from the National Science Fund for Distinguished Young Scholars of China (Grant no. 51125019) and Science and Technology Innovation Fund of Southwest Petroleum University (Grant no. GIFSB0701).

\section{References}

[1] G. T. Vladisavljević, I. Kobayashi, and M. Nakajima, "Effect of dispersed phase viscosity on maximum droplet generation frequency in microchannel emulsification using asymmetric straight-through channels," Microfluidics and Nanofluidics, vol. 10, no. 6, pp. 1199-1209, 2011.

[2] T. S. H. Leong, T. J. Wooster, S. E. Kentish, and M. Ashokkumar, "Minimising oil droplet size using ultrasonic emulsification," Ultrasonics Sonochemistry, vol. 16, no. 6, pp. 721-727, 2009.

[3] N. Vankova, S. Tcholakova, N. D. Denkov, I. B. Ivanov, V. D. Vulchev, and T. Danner, "Emulsification in turbulent flow. 1. Mean and maximum drop diameters in inertial and viscous regimes," Journal of Colloid and Interface Science, vol. 312, no. 2, pp. 363-380, 2007. 
[4] J.-L. Liu, R. Xia, B.-W. Li, and X.-Q. Feng, "Directional motion of droplets in a conical tube or on a conical fibre," Chinese Physics Letters, vol. 24, no. 11, pp. 3210-3213, 2007.

[5] X.-Y. Peng, J. Zhang, T.-J. Liang et al., "Double jet emission of hot electrons from a micro-droplet spray," Chinese Physics Letters, vol. 21, no. 4, pp. 693-696, 2004.

[6] D. E. Woodmansee and T. J. Hanratty, "Mechanism for the removal of droplets from a liquid surface by a parallel air flow," Chemical Engineering Science, vol. 24, no. 2, pp. 299-307, 1969.

[7] D. F. Tatterson, J. C. Dallman, and T. J. Hanratty, "Drop sizes in annular gas-liquid flows," AIChE Journal, vol. 23, no. 1, pp. 68-76, 1977.

[8] P. Andreussi, G. Romano, and S. Zanelli, "Drop size distribution in annular mist flow," in Proceedings of the 1st Conference on Liquid Atomisation and Spray Systems, Tokyo, Japan, 1978.

[9] T. Ueda, "Entrainment rate and size of entrained droplets in annular two-phase flow, Bulletin of the JSME, vol. 22, no. 171, pp. 1258-1265, 1979.

[10] M. Sevik and S. H. Park, “The splitting of drops and bubbles by turbulent fluid flow," Journal of Fluids Engineering, vol. 95, no. 1, pp. 53-60, 1973.

[11] B. Azzopardi, G. Freeman, and D. King, "Drop sizes and deposition in annular two-phase flow," UKAEA Report AERER9634, 1980.

[12] J. C. B. Lopes and A. E. Dukler, Droplet Sizes, Dynamics and Deposition in Vertical Annular Flow, 1985.

[13] G. Kocamustafaogullari, S. Smits, J. Razi, and W. Huang, "Droplet size modelling in annular flow," in Proceedings of the 6th International Topical Meeting on Nuclear Reactor Thermal Hydraulics, 1993.

[14] B. J. Azzopardi, A. Piearcey, and D. M. Jepson, "Drop size measurements for annular two-phase flow in a $20 \mathrm{~mm}$ diameter vertical tube," Experiments in Fluids, vol. 11, no. 2-3, pp. 191-197, 1991.

[15] U. Shavit and N. Chigier, "fractal dimensions of liquid jet interface under breakup," Atomization and Sprays, vol. 5, no. 6, pp. 525-543, 1995.

[16] Z. Weixing, Z. Tiejun, W. Tao, and Y. Zunhong, "Application of fractal geometry to atomization process," Chemical Engineering Journal, vol. 78, no. 2-3, pp. 193-197, 2000.

[17] W.-X. Zhou and Z.-H. Yu, "Multifractality of drop breakup in the air-blast nozzle atomization process," Physical Review E, vol. 63, no. 1, Article ID 016302, 6 pages, 2001.

[18] S. V. Apte, M. Gorokhovski, and P. Moin, "LES of atomizing spray with stochastic modeling of secondary breakup," International Journal of Multiphase Flow, vol. 29, no. 9, pp. 1503-1522, 2003.

[19] M. A. Gorokhovski and V. L. Saveliev, "Analyses of Kolmogorov's model of breakup and its application into Lagrangian computation of liquid sprays under air-blast atomization," Physics of Fluids, vol. 15, no. 1, pp. 184-192, 2003.

[20] H.-F. Liu, X. Gong, W.-F. Li, F.-C. Wang, and Z.-H. Yu, "Prediction of droplet size distribution in sprays of prefilming air-blast atomizers," Chemical Engineering Science, vol. 61, no. 6, pp. 1741-1747, 2006.

[21] D.-J. Jiang, H.-F. Liu, W.-F. Li, J.-L. Xu, F.-C. Wang, and X. Gong, "Modeling atomization of a round water jet by a high-speed annular air jet based on the self-similarity of droplet breakup," Chemical Engineering Research and Design, vol. 90, no. 2, pp. 185-192, 2012.
[22] M.-J. Yun, B.-M. Yu, P. Xu, and J.-C. Cai, "Fractal analysis of power-law fluid in a single capillary," Chinese Physics Letters, vol. 25, no. 2, pp. 616-619, 2008.

[23] Y. Mei-Juan and Z. Wei, "Fractal analysis of Robertson-Stiff fluid flow in porous media," Chinese Physics Letters, vol. 29, no. 6, Article ID 064706, 2012.

[24] M. Yun, B. Yu, and J. Cai, "Analysis of seepage characters in fractal porous media," International Journal of Heat and Mass Transfer, vol. 52, no. 13-14, pp. 3272-3278, 2009.

[25] Y. Mei-Juan, Z. Wei, L. Yun-Bao, and L. Yu, "Fractal analysis of Herschel-Bulkley fluid flow in a capillary," Acta Physica Sinica, vol. 61, no. 16, Article ID 164701, 2012.

[26] M. Yun, B. Yu, and J. Cai, "A fractal model for the starting pressure gradient for Bingham fluids in porous media," International Journal of Heat and Mass Transfer, vol. 51, no. 5-6, pp. 1402-1408, 2008.

[27] M.-J. Yuan, B.-M. Yu, W. Zheng, and J. Yuan, "Fractal analysis of Casson fluid flow in porous media," Acta Physica Sinica, vol. 60, no. 2, Article ID 024703, 2011.

[28] B. J. Azzopardi and J. C. F. Teixeira, "Detailed measurements of vertical annular two-phase flow-part I: drop velocities and sizes," Journal of Fluids Engineering, vol. 116, no. 4, pp. 792-795, 1994.

[29] L. B. Fore and A. E. Dukler, "The distribution of drop size and velocity in gas-liquid annular flow," International Journal of Multiphase Flow, vol. 21, no. 2, pp. 137-149, 1995.

[30] J. O. Hinze, "Fundamentals of the hydrodynamic mechanism of splitting in dispersion processes," AIChE Journal, vol. 1, no. 3, pp. 289-295, 1955.

[31] A. W. Adamson, Physical Chemistry of Surfaces, John Wiley \& Sons, New York, NY, USA, 5th edition, 1990.

[32] F. M. White, Viscous Fluid Flow, McGraw-Hill, New York, NY, USA, 2nd edition, 1991.

[33] H.-Q. Zhang, W. Qian, C. Sarica, and J. P. Brill, "A unified mechanistic model for slug liquid holdup and transition between slug and dispersed bubble flows," International Journal of Multiphase Flow, vol. 29, no. 1, pp. 97-107, 2003.

[34] Y. Taitel, D. Bornea, and A. E. Dukler, "Modelling flow pattern transitions for steady upward gas-liquid flow in vertical tubes," AIChE Journal, vol. 26, no. 3, pp. 345-354, 1980.

[35] X. T. Chen, X. D. Cai, and J. P. Brill, "A general model for transition to dispersed bubble flow," Chemical Engineering Science, vol. 52, no. 23, pp. 4373-4380, 1997.

[36] X.-H. Tan, X.-P. Li, and J.-Y. Liu, "Model of continuous liquid removal from gas wells by droplet diameter estimation," Journal of Natural Gas Science and Engineering, vol. 15, pp. 8-13, 2013. 


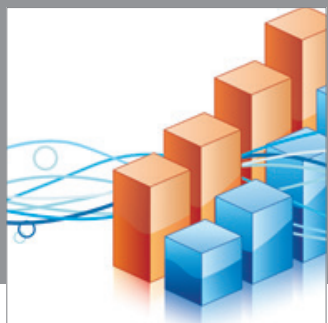

Advances in

Operations Research

mansans

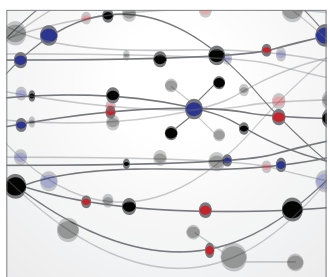

The Scientific World Journal
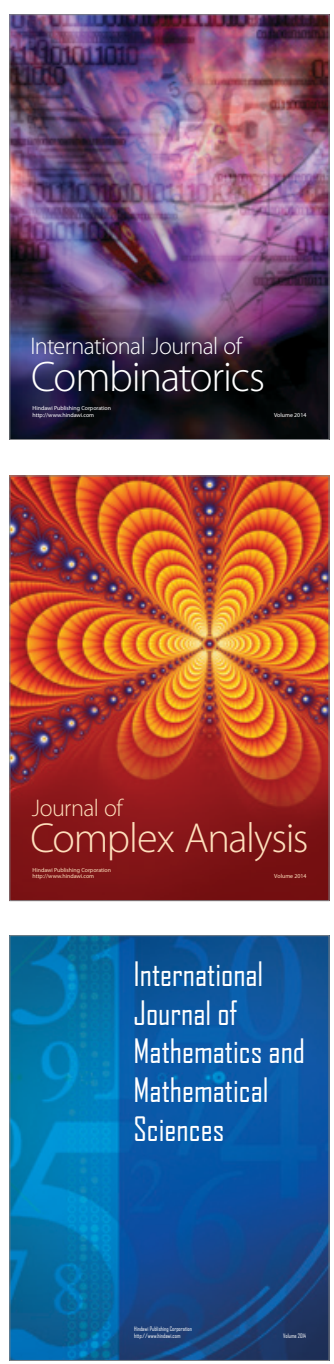
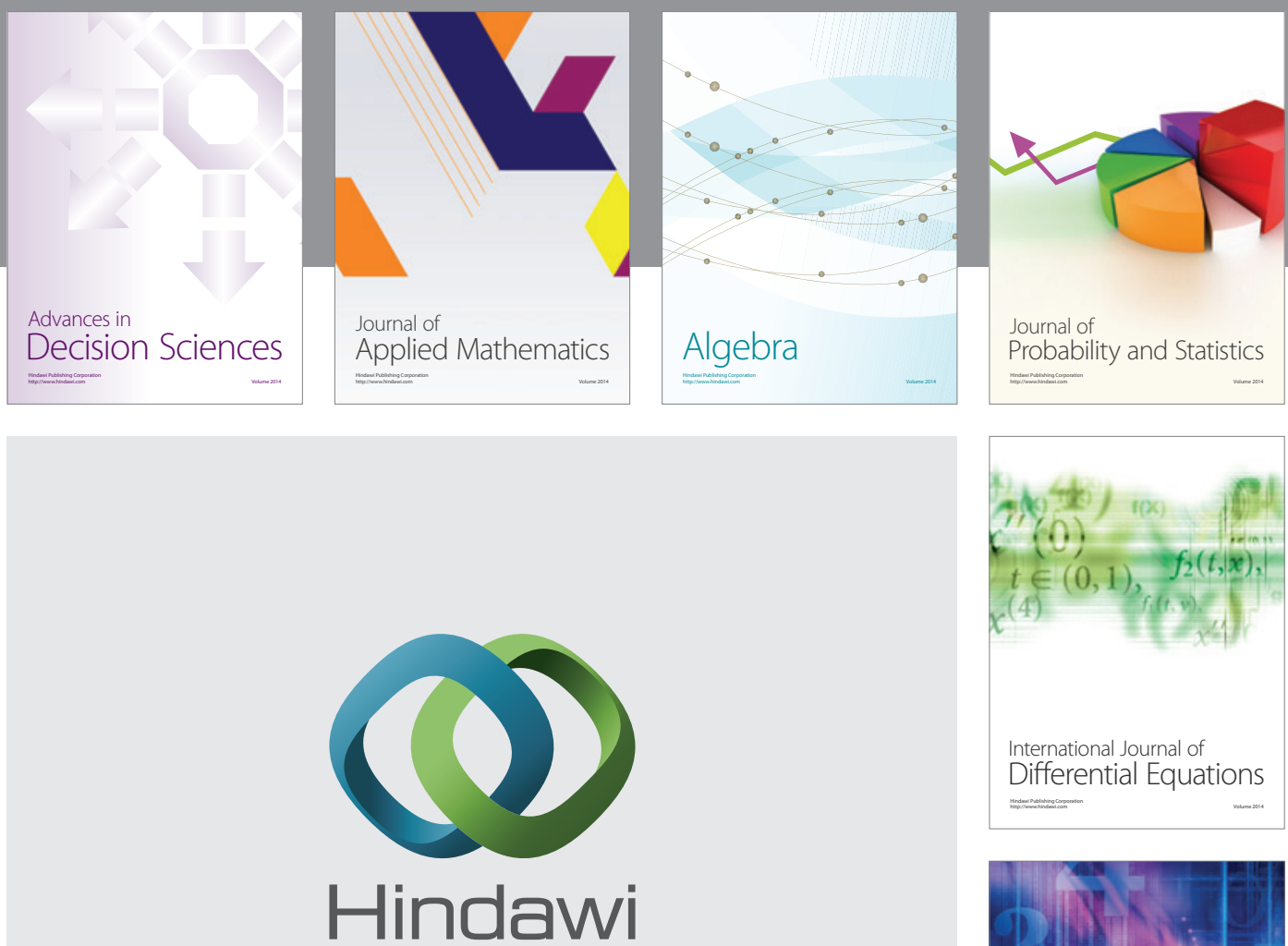

Submit your manuscripts at http://www.hindawi.com
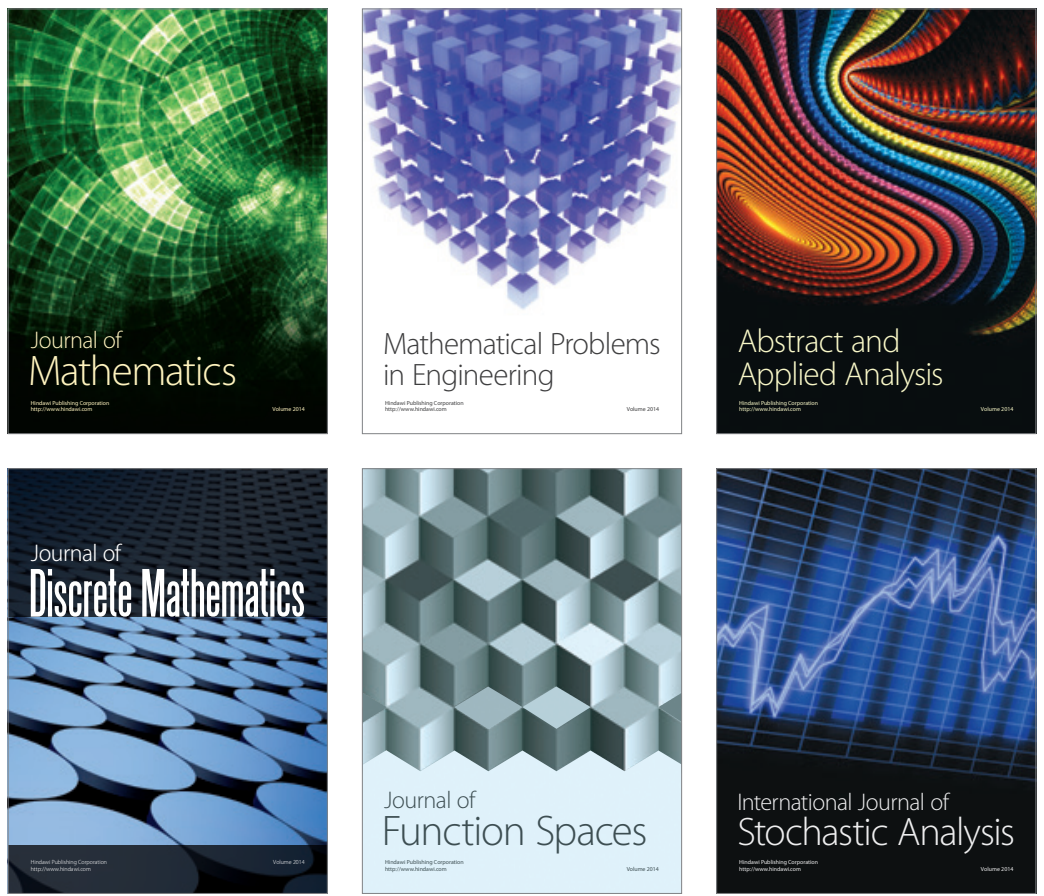

Journal of

Function Spaces

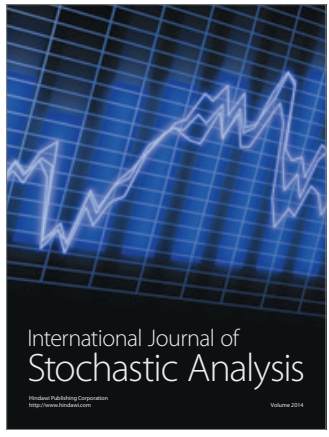

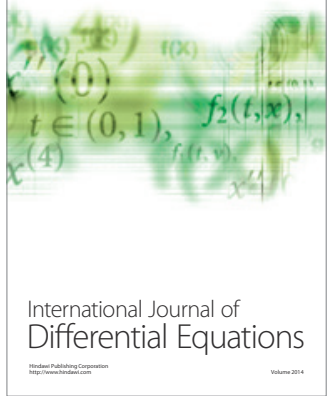
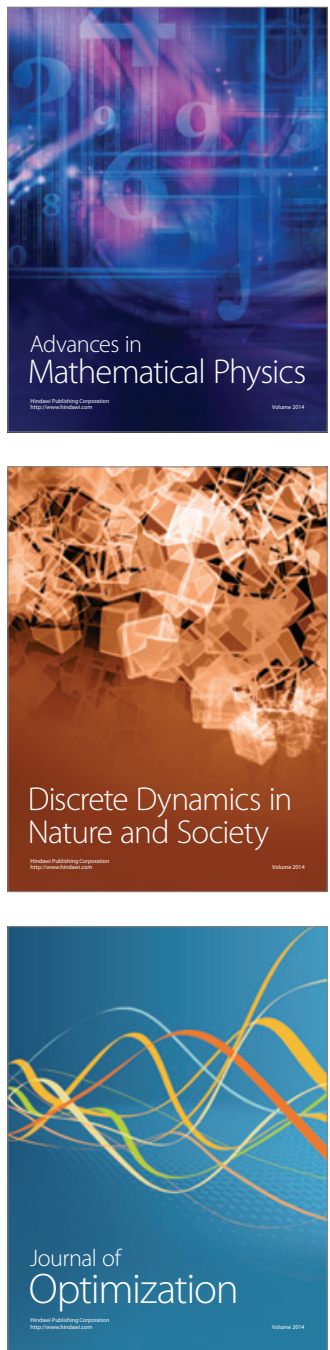